\title{
Augmented Education: an Opportunity for Digital Inclusion on Mexican Secondary Schools
}

\author{
Pedro C. Santana, Celso U. Juárez \\ IHCLab, School of Telematics \\ University of Colima \\ Colima, Mexico \\ \{psantana, celso_juarez\}@ucol.mx
}

\author{
Martha A. Magaña \\ School of Pedagogy \\ University of Colima \\ Colima, Mexico \\ mc2103@ucol.mx
}

\begin{abstract}
This work proposes a mobile augmented reality system to improve Mexican secondary education, allowing students to access additional educational contents related to their textbooks. Our application recognize the augmented tags in the book and shows multimedia contents to complement the topics covered in the class. Usability testing of our augmented reality system showed a high user satisfaction.
\end{abstract}

Keywords- Augmented reality; Mexican Secondary Education; Mobile computing

\section{INTRODUCTION}

Teaching methods used worldwide are constantly evolving and involve new technologies in these changes. For example, at the beginning of 20th century, movies were adopted as an educational tool in American schools [1]. In the 1990s, with the worldwide adoption of the Web, content on the Internet and digital communications were well received in education. In the early twenty-first century, great advances in mobile technologies are enabling us to make use of technologies such as augmented reality (AR) in educational projects.

AR mixes virtual features with the real world. As its name suggests, it augments the real world with virtual information [2]. While the concept was created in the $60 \mathrm{~s}, \mathrm{AR}$ is a technology that allows developing, distributing and using virtual augmented applications on a large scale. The boom of mobile devices with high processing capabilities and the presence of cameras in virtually all recent mobile devices make a great support for AR applications. Currently, there are several prototypes of AR systems applied to education. Some examples are [3], [4] and [5].

Our work aims to support basic education students to improve the understanding of the topics covered in their textbooks using only their own mobile phones. To understand the challenges and circumstances around the subject, we conducted interviews with a group of them in a public secondary school. Those interviews served to inform our design of a system that aims at improving the learning process of these students. The main concept behind the proposed solution is a mobile augmented reality system, through which students can enrich their experience with textbooks, using augmented contents, like videos, music or 3D models. We argue that this system will allow students to engage more with classroom activities, and will have a positive impact on their learning.

\section{CONTEXTUAL STUDY}

Our field work was designed to know the characteristics of their cell phones. We focused on four main aspects: genre usage, time of use, brands and the camera component.

The methodology and the results of this contextual study were presented at [6], this study produced the following main results. We interview 30 students, 10 from each grade, randomly chosen from each grade in a public school.

Fig. 1 shows that $100 \%$ of interviewed men and $78 \%$ of interviewed women had a cellphone, which comprises $86 \%$ of the whole group.

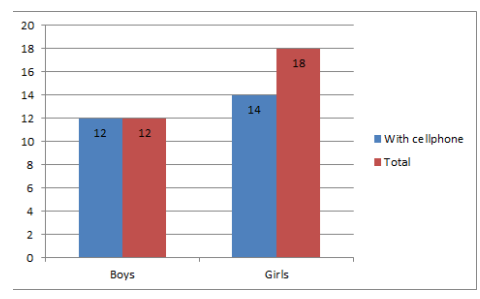

Figure 1. Statistics by genre.

Fig. 2 shows that of the 26 students that had a cell phone most of them got it within the last two years, which is the time most of them got into secondary school.

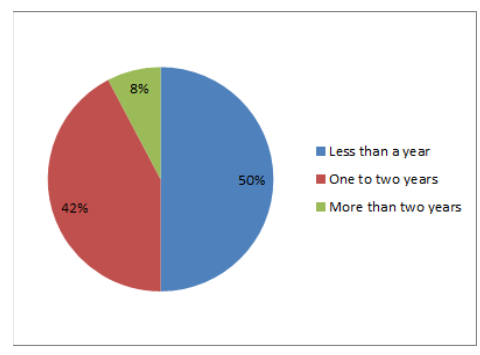

Figure 2. Statistics by time of use. 
Fig. 3 shows that of the 26 students interviewed that have a cell phone we found that the brand that most people use is LG, followed very close by Samsung and Sony Ericsson.

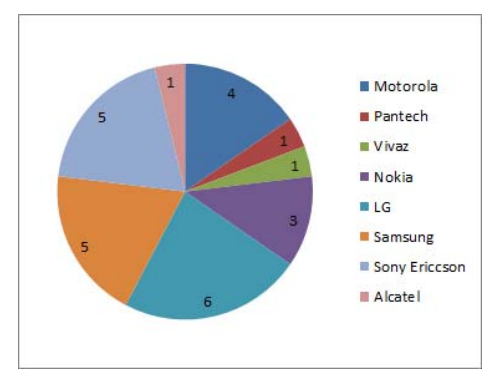

Figure 3. Statistics by cellphone brands.

Of the 26 interviewed students that had a cell phone we found that $96 \%$ of them had a cell phone with a built-in camera, as seen on Fig. 4. The camera is the most important element of an augmented reality system and this result indicates that currently it is very unlikely to find a recent cell phone without a built-in camera.

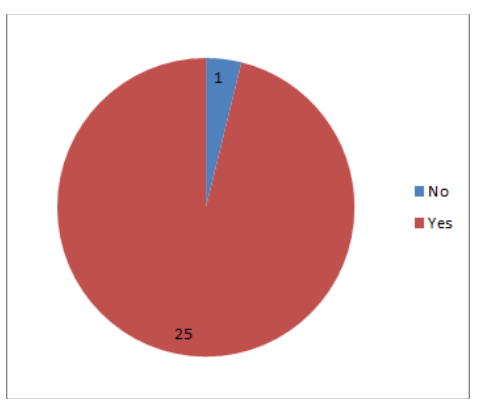

Figure 4. Statistics by cellphone with built-in camera.

We found in our study that almost the same number of male and female students use cell phones at the school. $96 \%$ of the students used regularly the built-in camera of their cell phones. Most of the cell phone ran Android operating system.

\section{RELATED WORK}

In this section we compare some alternative approaches that have been discussed within the context of supporting education through augmented reality.

\section{A. Construct $3 D$}

This system uses augmented reality to support face to face collaboration between teachers and students. Its main advantage is that with AR students can see $3 \mathrm{D}$ projections of objects that otherwise they had to draw using pencil and paper. With Construct3D, students can work directly on threedimensional spaces, complex spatial problems, and spatial relationships and arguably understand those topics better using AR than using traditional methods (such as pencil and paper) [7].

The evaluation of this project was partially funded by the IBM Students for a Smarter Planet initiative.

\section{B. MagicBook}

It is a printed book that shows how the AR can be used in schools for educational purposes as an interesting method of teaching. Allows students to read a book like any traditional book or can be used with a screen to watch $3 \mathrm{D}$ virtual images out of the pages [8].

\section{ARSK}

It is a mobile augmented reality system developed by researchers from the Technological University of the Mixteca in Mexico; this system uses Android cell phones to show skeleton 3D models over augmented tags [9].

In contrast with those systems, we aimed to create a system that provides augmented content directly embedded into the actual textbooks, and displaying on their own mobile phones.

\section{DESIRED FEATURES OF THE SYSTEM}

In order to make that the AR supports basic education our system must have the next feature:

\section{A. Interface easy to use}

The system must have a very small learning curve and be as easy to use as possible. To achieve this, the AR interface must be properly designed and have gone through the necessary usability testing.

\section{B. Content should be generated by teachers}

To ensure validity of the information, the system should allow teachers to add contents on a particular topic.

\section{APPLICATION ARCHITECTURE}

To achieve the functionality of the system we propose the architecture shown in Fig. 5.

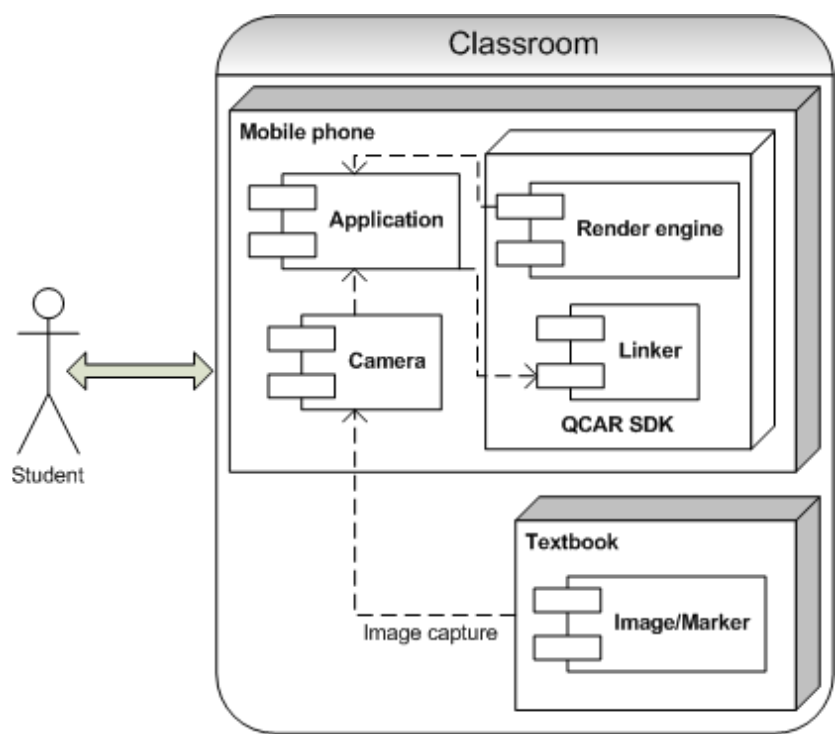

Figure 5. System architecture. 


\section{A. Classroom}

The classroom represents the teaching environment, where the following two components are present:

\section{B. Mobile phone}

On this component we can find the render engine which interprets the information from the mobile application through the linker; and by using some calculations it identifies what web service should be called in order to get the appropriate content. After doing that, the render engine receives the content from the web services and it sends the information that should be displayed to the application. This way the user can interact with it.

\section{Textbook}

This component represents the physical book, where the augmented tags or the image that is going to be tracked are located. They are linked to the application content. It is important to highlight that we have worked directly with the textbook when the image is big enough to be tracked by the camera, when it cannot be done, an augmented tag is used. The application gets the information from the image tracked using the device's camera and it sends it to the QCAR SDK to send the request into the application.

\section{DEVELOPMENT}

We developed a fully-functional system prototype. To create the 3D models we used Autodesk 3Ds Max. Also, we also used Creative Commons licensed 3D Models from [10].

The content was designed based on Unit 5 from the book "Historia I de Segundo Grado" Spanish for "History I for Second Grade", written by Gamboa Ramirez [11]. This unit covers topics of recent decades such as recent wars, contemporary conflicts, economic and social inequalities in the world, and the technological and scientific advances in recent years. The application is able to displays three type of contents: 3D models, Video and Audio.

The application was developed using the Android SDK. The device used for development was a HTC Droid Incredible smartphone running Android 2.3.3 and the Qualcomm Augmented Reality SDK (QCAR SDK), this platform uses superior, stable, and technically efficient computer visionbased image recognition and offers the widest set of features and capabilities, giving developers the freedom to extend their visions without technical limitations. The development environment used was Unity $3 \mathrm{D}$ with the official extension to develop using QCAR SDK.

Next we discuss the results achieved with the mobile application development.

The Fig. 6 show the design of the application when it displays a 3D model.

In the lower area is shown the zoom controls of the camera. Most of the screen is occupied by the image obtained by the camera in real time. The book has a marker that the system identifies and, based on a comparison with the database, it displays a 3D model that is found on the cloud and can be obtained through a web service.

The model can be viewed from any angle as long as the marker is not completely out of sight of the camera.

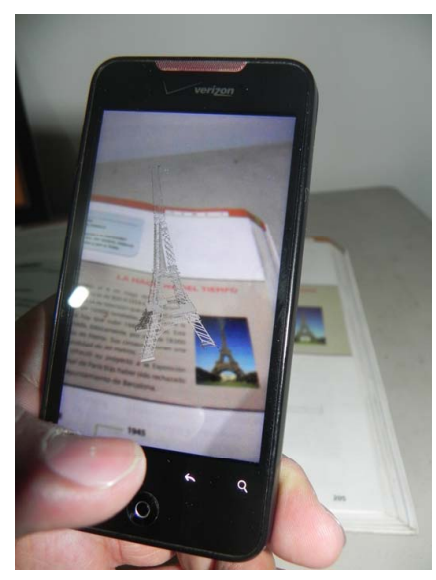

Figure 6. 3D model.

Fig. 7 shows the video playback. The system searches the marker in the content repository and gets the video file related to it.

The video player is shown in the foreground and the user can interact with its controls (volume, pause and full screen). When the user wants to terminate the action he uses the back button included in all Android devices.

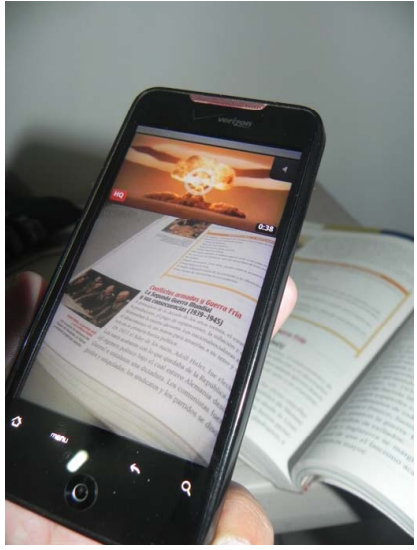

Figure 7. Video playback.

Fig. 8 shows the playback of an audio file recovered from the cloud. Just as with the video, the player will remain at the forefront regardless of whether the marker leaves the field of view of the camera and regardless of what it captures. The user can interact with audio controls and the timeline of the playback. When the user wants to stop using the application he uses the navigation buttons provided on all Android devices. 


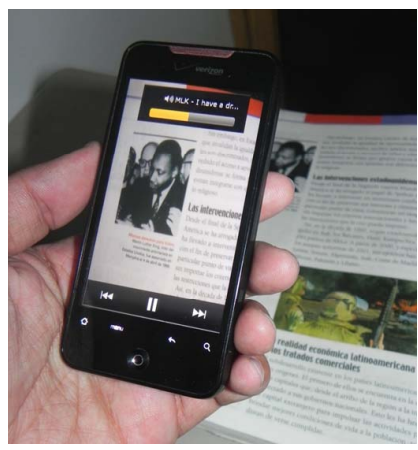

Figure 8. Audio playback.

\section{PRELIMINARY EVALUATION}

To explore the feasibility of the conceptual design, a preliminary evaluation was conducted. We applied a number of usability tests to see if our AR application can be used as an educational tool and to assess its application and validate how easy to use is. The tests were carried out at the HumanComputer Interaction laboratory (IHCLab) from the University of Colima, Mexico.

\section{A. Preliminary evaluation protocol}

According to [12] the usability evaluation included 5 participants with an age average of 12 years old (two females and three males). They previously had studied unit 5 of the textbook "Universal History I". The five participants had previous experience using smartphones.

The evaluation session lasted about one hour. The first step of the test consisted of completing a pre-questionnaire to measure previous knowledge on the subject (universal history), which included topics such as Second World War, the Eiffel Tower, and the life and work of Martin Luther King. The second step of the test was to show and explain the participants how our AR worked. The next step was to ask participants to open the book and point the cell phone's camera to one of the markers to get more information on the topic being read in the book. After that, participants completed a post-questionnaire to measure the knowledge after the usability test (on the same topics of the pre-questionnaire) and an evaluation questionnaire assigning a usability score ranking from 1 (very poor usability) to 10 (excellent usability).

\section{B. Preliminary usability Test Results}

Data collected from the first questionnaire gave an average of 7.9/10. At the time of the usability testing, the students were surprised with the augmented contents of their textbooks and remained focused until all the content was played. Of the five participants, the student who took longer to find the augmented content was the related to the second world war ( 4 minutes and 2 seconds), because this content, instead of using an augmented tag, it is played by directing the camera to an image of the same book, this finding indicates that we are not yet accustomed to the mixture of physical reality and virtual reality without special markers. After the usability test, students answered the questionnaire again, this time the obtained average was 9.4/10 (see Fig. 9). Finally the children evaluated the degree of satisfaction with the application using a scale of 1 to 10 achieved a $97 \%$ satisfaction $(10,10,9.5,10,9)$.

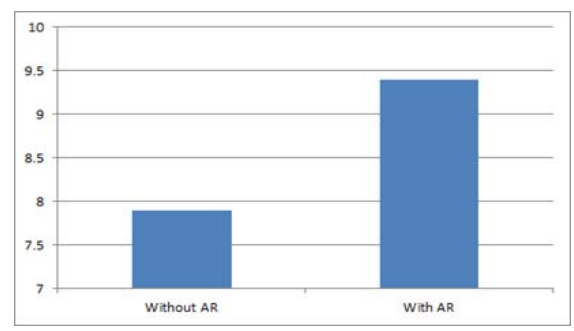

Figure 9. Evaluation of knowledge on history.

\section{EVALUATION}

After the preliminary evaluation, we noticed that in order to have a better context of the interaction with the system and observe the reactions of the learners, we needed to go directly to the classrooms. Also based on preliminary results we develop a new version of the prototype including the augmented tags for all the contents.

\section{A. Participants}

The test took place in the Secondary School Number 1 of the city of Colima (see Figure 4); we had 29 students, 52\% male and $48 \%$ female with an average age of 13 years old. $28 \%$ of the learners dislike the History class. $76 \%$ are users of cellphones and $100 \%$ unknown augmented reality. The evaluation also included the history teacher of the group.

\section{B. Procedure}

The sessions were video recorded and the observers took photographs and notes. The evaluation was carried out following a protocol of evaluation that described each step along the whole test, as follows.

First, we explained to the teacher the concept and functionality of the system; we asked her help observing the behavior and reactions of the students. Finally we asked some questions about her opinion about the prototype from the given explanation.

After the introduction with the teacher, the evaluation with the students started with the introduction to the system and a review of the history class, this review was given by students of the School of Pedagogy of our University; the subjects were: Eiffel tower, Martin Luther King and Second World War.

After the review we requested the student to use the prototype following the phases given in the review.

At the end of the hands on evaluation with the learners (see Fig. 10) they answered a usability questionnaire and a final interview was made to the teacher, asking her observations in the sessions about the reaction of the children, differences between the activities carried out in a traditional way and the ones using the system, and also their general opinions. 


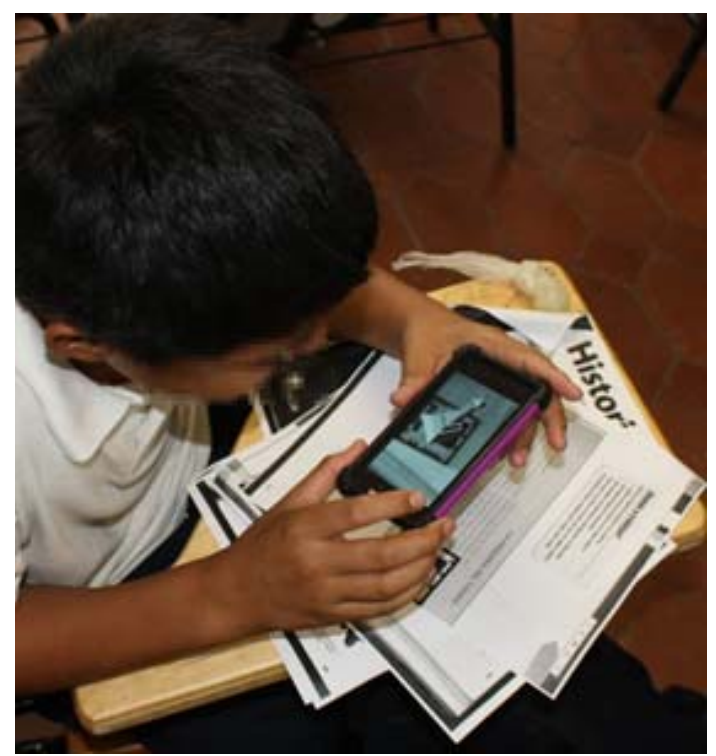

Figure 10. User evaluation.

\section{Results}

After analyze all the collected data, the following results were obtained:

$79 \%$ of the students prefer the $3 \mathrm{D}$ model as their preferred augmented content, followed by video with $21 \%$. While $38 \%$ indicated having problems with audio content, mainly because the noise in the classroom.

The question "Would you believe the use of this software will improve your learning?" gave us that $62 \%$ of the children believe the software will improve their learning. Some of the related comments are:

"I would learn more about technology"

"I learn more"

"Brings me more information"

"Using technology is more fun"

It is important remark, that one child said "I do not believe this software will improve my learning because I would be fascinated with it"

The opinions of the teacher were very positive, mentioned that she is very interested on using the system in her classes and she wants to call us to participate in the regular classes when she is teaching these subjects.

\section{CONCLUSIONS}

In this paper we described a mobile augmented reality application and the usability test done to it. Results of the evaluation suggest that augmented reality applications can strongly improve secondary education in Mexico.
We found in the usability evaluation that our educational AR system was well received by secondary school students. The system would provide a richer mechanism to complement lecture contents.

Although nowadays not all students in middle school are able to access smartphones, these conditions are likely to change as the background study indicates and the prices of the smartphones continue dropping.

As a general conclusion we can say that the use of mobile phones as a platform to deploy augmented reality applications for education is adequate.

\section{ACKNOWLEDGMENT}

We thank the Secondary School Number 1 of Colima for their collaboration and facilitations for us to do our study.

Thanks to the students of the School of Telematics Arantxa Villaseñor, Eneida Sánchez, Enrique Amezcua and Jesus González; as well as Brianda Montes, Laura Silva and Erika Avalos from the School of Pedagogy for their help in the application of the tests and the data gathering.

The evaluation of this project was sponsored by the IBM Students for a Smarter Planet Initiative.

\section{REFERENCES}

[1] R M. Gagné (1987). Instructional technology: foundations (págs. 13-14).

[2] Azuma, R. T. (1997). A Survey of Augmented Reality. En Teleoperators and Virtual Environments (págs. 355-- - 385). Malibu, CA.

[3] Guillaume Zufferey, P. J., Pierre Dillenbourg, Danie Cunliffe. (2008). A tabletop learning environment for logistics assistants: activating teachers.

[4] F. Liarokapis, N. Mourkoussis, M. White, J. Darcy, M. Sifniotis, P. Petridis, A. Basu, and P. F. Lister. Web3D and augmented reality to support engineering education. World Trans. Engineering and Technology Education, 3(1):1-4, 2004.

[5] Corrales, K. C. Sistema de realidad aumentada para el aprendizaje de la lectoescritura. CiCOMP 2011. Ensenada, México.

[6] Juárez, C., Santana, P., \& Magaña, M. (2012). Mobile Augmented Reality to support basic education in Mexico. Educational Interfaces, Software, and Technology 2012 (EIST) at CHI 2012. Austin, Texas.

[7] Hannes Kaufmann, D. S. (2003). Mathematics and geometry education with collaborative augmented reality. Computers \& Graphics.

[8] Mark Billinghurst, Hirokazu Kato, and Ivan Poupyrev. 2001 MagicBook: transitioning between reality and virtuality. In CHI '01 extended abstracts on Human factors in computing systems (CHI EA '01). ACM, New York, NY, USA, 25-26.

[9] E. Ramos, E. P. C., Jorge Hernández, Mónica García, Hugo Martínez, Moisés Ramírez, Omar Cruz, Alfonso López, Myriam Reyes. (2010). ARSK: an edutainment application using augmented reality for basic education children to strength the knowledge of the human skeleton.

[10] Blend Swap (2011). Recuperado el 13 de noviembre de 2011, de http://www.blendswap.com/

[11] R. Gamboa, A. Cedillo (2009). Historia 1 Segundo Grado. Ciudad de México, México: Editorial Macmillan.

[12] Nielsen, J. (2000). Why you only need to test with 5 users. Test. Alertbox. Retrieved from http://www.useit.com/alertbox/20000319.html 